Department of Population Studies, London School of Hygiene and Tropical Medicine, London, UK; ${ }^{3}$ University of Washington, Seattle, Washington State, USA

Objective The objective of this paper is to examine the association between marital status and the risk of HIV infection in the informal settlements of Nairobi. The findings from this study will inform HIV prevention programs, particularly among poor and marginalised groups in the informal settlements.

Methods Data are derived from a cross-sectional population-based survey nested in an ongoing Demographic Surveillance System (DSS) in two urban informal settlements in Nairobi city, where a total of about 60000 individuals living 23000 households are under surveillance. Descriptive statistics and multivariate logistic regression analysis were used to describe the characteristics of the sample, as well as to assess the association between marital status and risk of HIV infection.

Results The HIV prevalence of respondents who were divorced, separated or widowed was $27 \%$, among those who were married was $12 \%$, and among those who were never married was $5 \%$. Married respondents $(\mathrm{OR}=1.78$; $\mathrm{p}$ value $<0.05)$ and those who were divorced, separated or widowed $(\mathrm{OR}=4.06$; $\mathrm{p}$ value $<0.001)$ were significantly more likely to be infected with HIV compared to respondents who were never married. Circumcision was also a significant predictor of HIV infection. Men who were circumcised $(\mathrm{OR}=0.36$; $\mathrm{p}$ value $<0.05)$ were less likely to be HIV positive compared to those who were not circumcised.

Conclusion There is need for HIV prevention interventions to adopt a more targeted approach, particularly with regard to designing and implementing programs geared towards addressing the increased risk of HIV infection among married people and those who were formerly married.

\section{P2-432 PATTERNS AND DETERMINANTS OF BREASTFEEDING AND COMPLEMENTARY FEEDING PRACTICES IN URBAN INFORMAL SETTLEMENTS, NAIROBI, KENYA}

doi:10.1136/jech.2011.142976l.62

${ }^{1} \mathrm{E}$ Kimani-Murage, ${ }^{2} \mathrm{~N}$ Madise, ${ }^{1} \mathrm{~J}-\mathrm{C}$ Fotso, ${ }^{1} \mathrm{C}$ Kyobutungi, ${ }^{*} \mathrm{M}$ Kavao, ${ }^{3} \mathrm{~T}$ Gitau, ${ }^{1} \mathrm{~N}$ Yatich. ${ }^{1}$ African Population and Health Research Center, Nairobi, Kenya; ${ }^{2}$ University of Southampton, Southampton, UK; ${ }^{3}$ University of the Witwatersrand, Johannesburg, South Africa

Introduction Little evidence exists on breastfeeding and infant feeding practices in urban slums in sub-Saharan Africa. Our aim was to assess breastfeeding and infant feeding practices in Nairobi slums with reference to WHO recommendations.

Methods Data from a longitudinal study conducted in two Nairobi slums are used. The study involves 4299 children aged 0-42 months, born between September 2006 and January 2010, for the period they were infants. All women who gave birth during this period were interviewed on breastfeeding and complementary feeding practices at recruitment and this information was updated twice, at 4-monthly intervals. Cox proportional hazard analysis was used to determine factors associated with cessation of breastfeeding in infancy and early introduction of complementary foods.

Results There was universal breastfeeding with almost all children (99.0\%) having ever been breastfed, and $85 \%$ were still breastfeeding by the end of the $11^{\text {th }}$ month. Exclusive breastfeeding for the first 6 months was rare (2\%). Factors associated with sub-optimal infant breastfeeding and feeding practices in these settings include child's sex; perceived size at birth; mother's marital status, ethnicity, and education level; pregnancy desirability; place of delivery; and slum of residence.

Conclusions The study indicates poor adherence to WHO recommendations for breastfeeding and infant feeding practices. Breastfeeding and infant feeding patterns are associated with child, maternal and household level characteristics. Interventions and further research should pay attention to factors such as cultural practices, access to and utilisation of healthcare facilities, child feeding education, and family planning.

\section{P2-433 NUTRITIONAL SUPPLEMENTATION IN EARLY LIFE AND FUTURE RISK OF OBESITY: LONG-TERM FOLLOW-UP OF THE HYDERABAD NUTRITION TRIAL}

doi:10.1136/jech.2011.142976l.63

${ }^{1} \mathrm{~S}$ Kinra, ${ }^{*} \mathrm{H}$ Kuper, ${ }^{2} \mathrm{~K}$ V R Krishna, ${ }^{3} \mathrm{~A}$ Taylor, ${ }^{2} \mathrm{~B}$ Kulkarni, ${ }^{3} \mathrm{Y}$ Ben-Shlomo, ${ }^{3} \mathrm{G}$ D Smith, ${ }^{1} \mathrm{~S}$ Ebrahim. ${ }^{1}$ London School of Hygiene \& Tropical Medicine, London, UK; ${ }^{2}$ National Institute of Nutrition, Hyderabad, India; ${ }^{3}$ University of Bristol Department of Social Medicine, Bristol, UK

Introduction Nutritional supplementation programmes for pregnant women and young children exist in much of the developing world, but their long term health consequences, particularly in the context of nutrition transition, are unknown.

Methods The Hyderabad Nutrition Trial was a community trial to evaluate a supplemental nutrition programme for pregnant women and young children ( $<6$ years), conducted in 29 villages (15 intervention, 14 control) near Hyderabad city in India during 1987-1990. The supplement was a cereal based meal providing $2 \mathrm{MJ}$ calories and $20 \mathrm{~g}$ protein per day. Children born during the trial period were reexamined $\sim 20$ years later, and adiposity was assessed by DXA scans.

Results We recruited 1120 participants (27\% female) aged 18-21 years: 581 intervention and 539 controls. The body mass index of the intervention and control participants was similar $\left(19.3 \mathrm{~kg} / \mathrm{m}^{2}\right)$. There was some indication of greater adiposity in the intervention arm participants, but these differences were broadly consistent with chance. The total body fat (geometric mean) was $18.0 \%$ in the intervention arm, compared to $17.1 \%$ in the control arm (ratio: $1.04 ; 95 \%$ CI 0.99 to 1.09). The intervention and control arms had similar levels of central adiposity (8.5\% of the total body fat was in the L1L4 region).

Conclusion In this sample of rural Indians, modest protein-calorie supplementation in early life on the whole was not associated with greater total or central adiposity in young adulthood. Whether stronger differences emerge with age or progression of nutrition transition remains to be established.

\section{P2-434 TRENDS AND EPIDEMIOLOGIC FEATURES OF TUBERCULOSIS IN THE WEST AZERBAIJAN PROVINCE OF IRAN, 2004-2009}

doi:10.1136/jech.2011.142976l.64

${ }^{1}$ G Kolifarhood, ${ }^{*}$ S Dastgiri, ${ }^{3,4}$ S Salarilak, ${ }^{1} \mathrm{~N}$ Khosravi, ${ }^{4} \mathrm{~A} N$ Nejad, ${ }^{4} \mathrm{D}$ Khorasani, ${ }^{4} \mathrm{~B}$ Neamati, ${ }^{4} \mathrm{~A}$ Yousefzade, ${ }^{4} \mathrm{P}$ Mikaili, ${ }^{4} \mathrm{Y}$ Mohammadpour, ${ }^{4} \mathrm{R}$ Ghareaghaji. ${ }^{1}$ Zanjan University of Medical Science, Zanjan, Iran; ${ }^{2}$ Tabriz University of Medical Science, East Azerbaijan, Iran; ${ }^{3}$ slamic Azad Univrsity of Iran, Tabriz Branch, Medical Faculty, Tabriz, Iran; ${ }^{4}$ Urmia University of Medical Science, West Azerbaijan, Iran

Objective To determine of epidemiologic patterns and recent trends of pulmonary and extrapulmonary tuberculosis in West Azerbaijan province of Iran, during 2004-2009.

Material and Methods In this cross-sectional study, we studied the data of 1323 TB new cases that have been recorded by TB Management Center of Vice-chancellor of health affairs in West Azerbaijan province of Iran. National census data of 2006 were used for determining the incidence rates. Cochran-Armitage test was used to analyse the incidence trends.

Results The incidence rate of tuberculosis at this province was declined from 10.16 to 7.85 per 100000 during 2004-2009. Despite of higher incidence rates in southern regions, its two districts 
significantly had declined trends in study period $(p<0.05)$. Trends of age-specific incidence rates for both of pulmonary, extrapulmonary, also for male and female cases were increased as $\chi^{2}=1265 ; \chi^{2}=307.7$, $\mathrm{p}=0.0001$ and $\chi^{2}=931 ; \chi^{2}=582, \mathrm{p}=0.0001$, respectively. Considering the national tuberculosis standard index, smear positive notification rate was in the range of expected levels $(58 \%-68 \%)$, but extrapulmonary incidence rates were more than the expected level.

Conclusion Regarding the higher incidence rates of tuberculosis in the southern regions of West Azerbaijan province of Iran, and despite of declined trends at some of districts at this region, it seems that more control and prevention activities are still needed, especially for the lower socioeconomic populations. Comparison of the demographic, socioeconomic status and specific incidence rates, revealed that the epidemiologic patterns of $\mathrm{TB}$ at this province have shifted from developing to developed countries status.

\section{P2-435 SPECIFIC RISK FACTORS ASSOCIATED WITH CORONARY HEART DISEASE IN INDIANS}

doi:10.1136/jech.2011.142976l.65

P Joshi, R Kumari, ${ }^{*}$ M Z Idris, N Ahmad, R K Saran, S M Natu. KG Medical University, Lucknow, Uttar Pradesh, India

Background The rapidly increasing burden of noncommunicable diseases is a key determinant of global public health. Coronary artery disease $(\mathrm{CAD})$ is the largest killer globally.

Objective To study the distribution and the effect of specific risk factors on Coronary Heart Disease in the adult population.

Study design Cross sectional study.

Sample size 1101 subjects.

Study area Rural and urban area of Lucknow District, Uttar Pradesh, India.

Study tool and Data collection Pre-designed and pre-tested interview in relation to smoking, passive tobacco smoking, alcohol consumption, physical activity, Blood pressure, BMI, central obesity, dietary history, mental status, diabetes, lipid profile was assessed.

Results The prevalence of coronary heart disease in the total study sample came out to be $7.1 \%$. The prevalence in urban was significantly higher than rural $8.8 \%$ and $3.8 \%$ respectively, $\mathrm{CHD}$ was higher in past smokers $(17.8 \%)$ than nonsmokers $(7.1 \%)$, passive tobacco smoking $(10.7 \%)$, hypertensive subjects $11.2 \%$ as compared to normotensive subjects $5.5 \%$, significant difference was found between overweight (M-9\%, F-20.9\%) and normal subjects (M-6.7\%, F-6.8\%), higher prevalence was observed among subjects having central obesity (M-8.6\%, F-6.4\%), Non vegetarian had higher CHD $(9.9 \%)$ as compare to vegetarian $(6.0 \%)$. CHD was more in subjects having mild depression (12.1\%) than normal subjects (6.5\%). The prevalence was higher in subjects having high total cholesterol (7.6\%) and low HDL level (9.5\%).

Conclusion CHD was higher in smokers, non vegetarian, hypertensive and depressive subjects. There was significant difference between Rural and Urban smokers. Passive tobacco smoking, Alcohol consumption, B.P, BMI, central obesity and overweight was significantly associated with CHD.

\section{P2-436 RURAL-URBAN MIGRATION IN RELATION TO DXA MEASURES OF ADIPOSITY IN INDIA}

\section{doi:10.1136/jech.2011.142976l.66}

${ }^{1} \mathrm{H}$ Kuper, ${ }^{*}{ }^{1} \mathrm{~S}$ Kinra, ${ }^{3} \mathrm{~K}$ V Radhakrishna, ${ }^{2} \mathrm{~A}$ Taylor, ${ }^{3} \mathrm{~B}$ Kulkarni, ${ }^{2} \mathrm{Y}$ Ben-Shlomo, ${ }^{1} S$ Ebrahim. ${ }^{1}$ LSHTM, London, UK; ${ }^{2}$ Bristol University, Bristol, UK; ${ }^{3}$ National Institute of Nutrition, Hyderabad, India

Introduction India is experiencing an epidemic of obesity, diabetes and coronary disease. This epidemic is largely attributed to rapid urbanisation, driven in part by rural-urban migration. The aim of this study is to investigate whether rural-urban migration is related to DXA measures of adiposity within the Hyderabad arm of the Indian Migrant Study.

Methods Migrants of rural origin, their rural dwelling sibs, and those of urban origin together with their urban dwelling sibs were invited to attend for a screening examination. Participants underwent DXA scanning to assess total body fat and abdominal fat. Anthropometric variables were also measured and participants were interviewed.

Results We recruited 253 rural non-migrant rural (RNM), 332 ruralurban migrants (RUM), and 125 urban non-migrant (UNM) participants. Overall, $54 \%$ were male and average age was 48 years. RNM had significantly lower total fat, in terms of kgs of fat and percentage body fat, compared to RUM and UNM among both men (RNM: $14.8 \mathrm{~kg}$ and 22.5\%; RUM: $18.0 \mathrm{~kg}$ and $25.5 \%$; UNM; $18.6 \mathrm{~kg}$ and $25.9 \%$ ) and women (RNM: $20.9 \mathrm{~kg}$ and $35.3 \%$; RUM: $24.7 \mathrm{~kg}$ and $38.3 \%$; UNM; $27.3 \mathrm{~kg}$ and $39.8 \%$ ). Abdominal fat mass was also significantly lower among RNM than the two urban groups in both men and women. The percentage of total body fat in the abdominal region was lower among RNM men than the two urban groups, but this difference was not apparent among women.

Conclusion Migration into urban areas is associated with increased obesity, which may drive other risk factor changes.

\section{P2-437 DISABILITY IN TRAFFIC ACCIDENTS' VICTIMS ADMITTED TO A TRAUMA HOSPITAL IN BELO HORIZONTE, BRAZIL}

doi:10.1136/jech.2011.142976l.67

R Ladeira, ${ }^{*}$ M da Silva, I Starling, A P Santos, E Rocha, K Alves, E Azevedo, G Petri, J D Fialho, C Simao-Filho. Joao XXIII - Hospital - FHEMIG, Belo Horizonte, Minas Gerais, Brazil

Introduction Traffic accidents are an important cause of morbidity and mortality around the world. The aim of this study is describe the characteristics, accident profile and injuries suffered by the victims and the occurrence of sequelae.

Methods The study included traffic accident victims admitted to Joao XXIII Hospital - FHEMIG up to $24 \mathrm{~h}$ after the event between 1 March and 15 July 2008. Patients were also interviewed 12 months after the accident. The study was funded by PPSUS/FAPEMIG.

Results 181 patients were interviewed 1 year after the accident. $85.6 \%$ were male. The age group with the highest number of accidents was the $20-30$ year-olds (47\% of the total). Motorcycle occupants were the most common type of victim-112 (61.9\%). $89.7 \%$ of the patients were not able to work following the accident. Moreover, $40 \%$ were still unable to return to their usual activities 12 months after the accident. $50 \%$ considered their health as good, compared to their health condition one year before and $36.4 \%$ considered their health as worse than the previous year. Around $73 \%$ of the victims presented some kind of sequela one year after the accident, although they were mostly minor.

Conclusions This study showed a predominance of young male motorcycle occupants among traffic accident victims admitted to the hospital. Furthermore, a high proportion of victims were unable to return to work (40\%), even one after the accident. This fact highlights the high burden brought on by traffic accidents.

\section{P2-438 ETHNIC AND AGE DIFFERENCES IN THE INCIDENCE OF TUBERCULOSIS IN BULGARIA}

doi:10.1136/jech.2011.142976l.68

\section{B Levterova, ${ }^{*}$ D Dimitrova. Medical University, Plovdiv, Bulgaria}

One-third of the world's population is infected with TB. TB is debilitating and contagious. Every year, more than 9 million people develop active TB and 1.7 million people die from the disease. In Bulgaria incidence was 25.1/100 000 in 1990. Due to various reasons, 